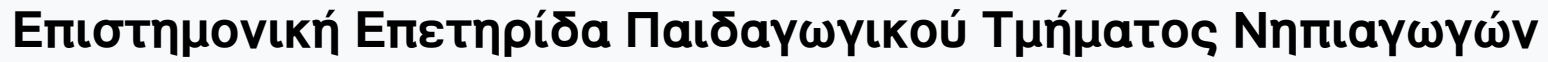 חavertotnuíou Iwavvívwv
}

Tóp. 5 (2012)

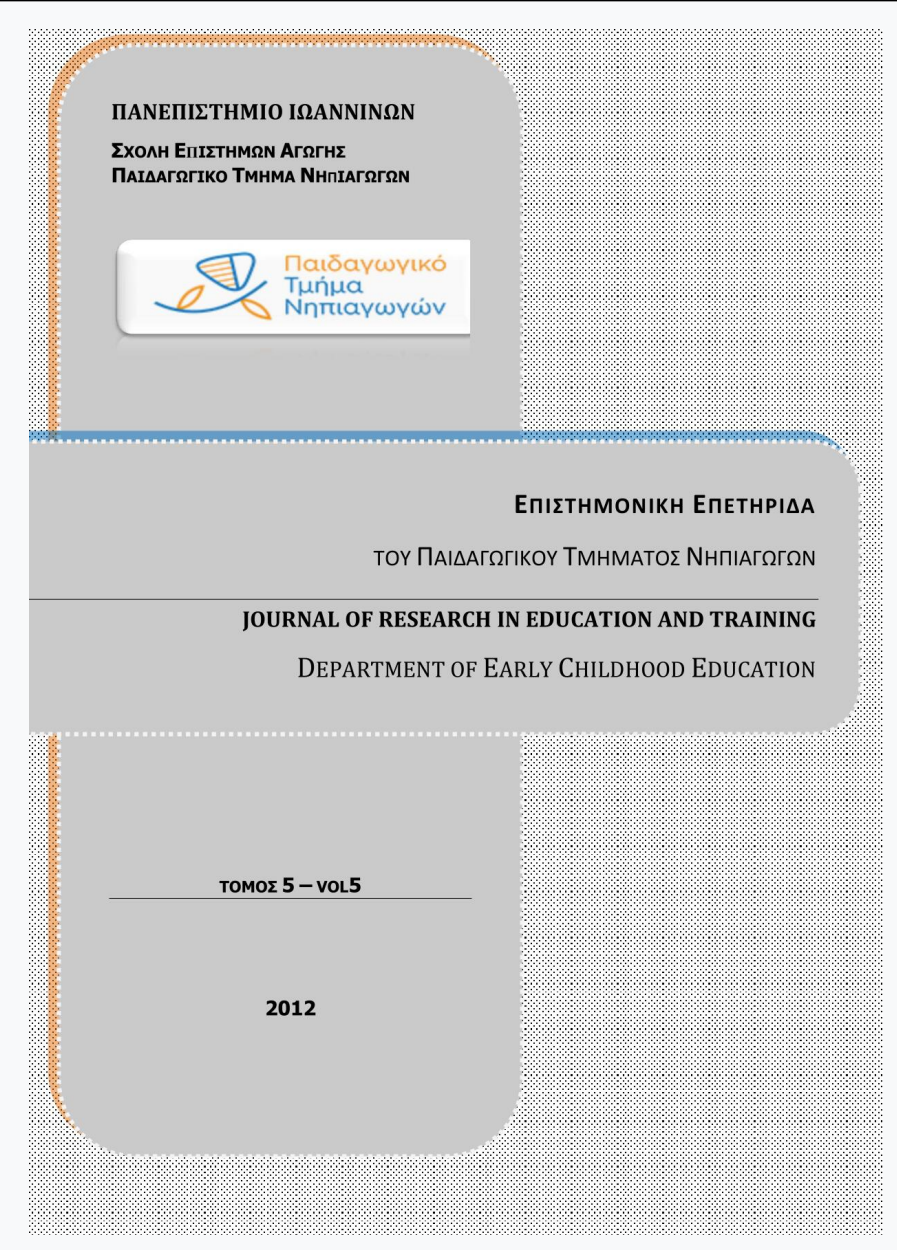

\section{Number sense in early and elementary mathematics education \\ Joke Torbeyns, Andreas Obersteiner, Lieven Verschaffel}

doi: $10.12681 /$ jret.8676

Copyright @ 2015, Joke Torbeyns, Andreas Obersteiner, Lieven Verschaffel

\section{(요요}

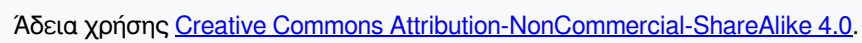

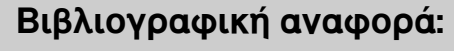

Torbeyns, J., Obersteiner, A., \& Verschaffel, L. (2015). Number sense in early and elementary mathematics education.

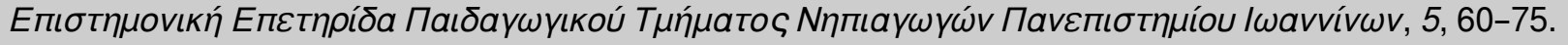
https://doi.org/10.12681/jret.8676 


\title{
Number sense in early and elementary mathematics education
}

\section{Joke Torbeyns, Andreas Obersteiner \& Lieven Verschaffel}

\begin{abstract}
Number sense is crucial in daily life and therefore an important aspect of education. The development of number sense recently attracted the attention of an increasing number of researchers in the domains of cognitive and developmental (neuro)psychology, (psychology of) mathematics education, special education, and educational neuroscience. In this article, we integrate and discuss the major results of these numerous studies on children's acquisition of number sense. We start with the definition of the concept of number sense. Afterwards, we summarize the major findings on children's acquisition of number sense from infancy to the early school years. Next, we provide an overview of recent intervention studies aiming at stimulating the development of number sense in young children. We end with a summary of the major findings and future issues for studies in this domain.
\end{abstract}

KEY-WORDS: Number sense; lower-order number sense; higher-order number sense; numerical magnitude representation; numerical magnitude comparison; number line estimation; mental number line; strategy competencies; intervention; number board games 


\section{INTRODUCTION}

Understanding number is very important in both children's and adults' lives. It is considered to be crucial for successful learning of mathematics at school and for dealing with the many numerical tasks in one's daily-life and professional activities. Moreover, research suggests that a very limited feeling for what the number symbols are conveying about quantities and for what mathematical operations do with these numbers, lies behind many people's restricted and superficial mastery of numbers and arithmetic (Dowker, 2005; McIntosh, Reys, \& Reys, 1992; Wagner \& Davis, 2010). The development of "number sense" recently attracted the attention of an increasing number of researchers in the domains of cognitive and developmental (neuro)psychology, (psychology of) mathematics education, special education, and educational neuroscience (e.g., Cirino \& Berch, 2010; Hatano, 2003; Kaufmann \& Dowker, 2009). In this article ${ }^{1}$, we integrate and discuss the major results of these numerous studies on children's acquisition of number sense. The article starts with the definition of the concept of number sense (section 1). Afterwards, we summarize the major findings on children's acquisition of number sense from infancy to the early school years (section 2). Next, we provide an overview of recent intervention studies aiming at stimulating the development of number sense in young children (section 3). We end with a summary of the major findings and future issues for studies in this domain (section 4).

\section{NUMBER SENSE: CONCEPTUAL FRAMEWORK}

As argued by many authors (Berch, 2005; McIntosh et al., 1992; Verschaffel, Greer, \& De Corte, 2007), no two researchers have defined the concept "number sense" in exactly the same way. Berch (2005) made a list of more than 30 alleged definitions or features of number sense. In an attempt to describe the major disparity in the meaning of the concept, Berch (2005) distinguished among a lower-order and a higher-order characterization of number sense.

The lower-order characterization of number sense, which is especially used by cognitive (neuro)psychologists (e.g., Ansari \& Karmiloff-Smith, 2002; Butterworth, 2005; Dehaene, 1997; Geary, 2010), limits the features of number sense to "elementary intuitions about quantity, including the rapid accurate perception of small numerosities and the ability to compare numerical magnitudes, to count, and to comprehend simple arithmetic operations" (Berch, 2005, p. 334). This 
characterization of number sense essentially involves the ability to represent and manipulate numerical quantities on a mental number line. This mental number line, or internal number line, refers to a language-independent analogical representation of numerical magnitude on which smaller numbers are represented more to the left and larger numbers more to the right (Dehaene, 2001).

Although these foundational components are incorporated in the higher-order perspective of number sense as well, this higher-order characterization, which is particularly found among mathematics educators, is considered to be much more complex and multifaceted (e.g., McIntosh et al., 1992; Nickerson \& Whitacre, 2010; Verschaffel \& De Corte, 1996; Yang, Li, \& Lin, 2008). Here number sense is defined as "a deep understanding of mathematical principles and relationships, a high degree of fluency and flexibility with operations and procedures, a recognition of and appreciation for the consistency and regularity of mathematics, and a mature facility in working with numerical expressions - all of which develop as a byproduct of learning through a wide array of mathematics education activities" (Berch, 2005, p. 334). Several researchers have composed lists of components of this higher-order characterization of number sense and attributes of students who possess it. Probably the most synthetic and influential framework for higher-order number sense is provided by McIntosh et al. (1992, p. 5) in the form of "a structure which clarifies, organises, and interrelates some of the generally agreed upon components of basic number sense". Their framework differentiates three areas where higher-order number sense plays a role. The first area is knowledge of and facility with numbers. Examples of subcomponents of this first area include a sense of orderliness of numbers, multiple representations for numbers, sense of relative and absolute magnitude of numbers, and a system of benchmarks. The second area, knowledge of and facility with operations, involves understanding the effect of operations, understanding mathematical properties, and understanding the relationship between operations. Finally, the third area, applying knowledge of and facility with numbers and operations to computational settings, comprises understanding the relationship between problem context and the necessary computation, awareness that multiple strategies exist, inclination to utilise an efficient representation and/or method, and inclination to review data and results for sensibility. Although this framework is generally accepted and frequently used within mathematics education as a helpful framework for teaching number sense, it has been criticised (Verschaffel et al., 
2007). From a scientific point of view, the broadness of the concept is considered to be a serious problem. As commented by Verschaffel et al. (2007) at the end of their review of research on whole number and arithmetic, in this higher-order characterization of number sense, "(...) number sense is, in most cases where we have encountered it, defined so broadly that it includes (...) most, if not all, other skills and dispositions (....) related to number and arithmetic".

\section{STUDIES ON THE DEVELOPMENT OF NUMBER SENSE IN YOUNG CHILDREN}

According to the above characterization of number sense, lower-order number sense is an inextricable part and a natural precursor of higher-order number sense. Many researchers have tried to unravel the characteristics and the development of lowerorder number sense in typically developing children. ${ }^{2}$ The relation between children's lower-order and higher-order number sense has only recently attracted the attention of researchers, limiting our current understanding of this relation. In this section, we discuss the major findings on the development of young children's lower-order number sense and its relation with their higher-order understanding of number.

First, numerous studies on the development of lower-order number sense in young children converge to the conclusion that infants and kindergartners are able to understand and manipulate numerical magnitude information using non-symbolic magnitude representations. In infants, lower-order number sense is typically investigated with the habituation paradigm (e.g., Xu \& Spelke, 2000), in which infants are presented with repeated representations of a numerosity. Once children's looking times habituate, a deviant numerosity is presented. If looking times increase when a deviant numerosity is presented, it is inferred that the infant was able to "detect the difference" between the habituated and deviant number. This ability increases with age: whereas 6-month-old infants are not able to detect the difference between numerosities with ratio 2:3 (e.g., 8 versus 12 dots), 10-monthold infants are (Xu \& Arriaga, 2007). In kindergartners, lower-order number sense is usually examined with comparison tasks (e.g., Halberda \& Feigenson, 2008). In these tasks, children have to decide which of two presented numerosities is the largest one (see Figure 1a for an example of such a comparison task). Typically, kindergartners succeed if the distance between the to be compared numerosities is large, but fail at small distances (= distance effect). However, similar to infant 
studies, their performance improves with increasing age. Furthermore, kindergartners' performances on non-symbolic comparison tasks are also characterised by a size effect, indicating that larger magnitudes have to be more distant from each other than smaller magnitudes in order to be discriminated accordingly. The size effect also decreases from infancy to adulthood, suggesting a higher sensitivity towards larger numerosities with increasing age. The above findings are all interpreted as an increasing precision of the representation of magnitude with age (Gallistel \& Gelman, 2000, 2005; Piazza et al., 2010) and are thought to reflect the characteristics of a numerosity representation similar to a mental number line. On this mental number line, numerosities are represented on a line with partially overlapping representations for nearby numerosities. As children develop, it is assumed that this overlap decreases, resulting in a better discrimination performance between numerosities (Noël, Rousselle, \& Mussolin, 2005).

A second major finding of empirical studies on the acquisition of lower-order number sense is that, over the course of development, young children also gradually develop the ability to represent magnitudes in a symbolic way with Arabic numerals. Successful mathematics development requires children to map these symbolic representations onto the pre-existing non-symbolic representations of magnitude (Lipton \& Spelke, 2005), a process by which formal numerical symbols acquire their meaning (Griffin, 2002). Using comparison tasks, in which children have to decide which of two presented Arabic numerals is the largest one (see Figure $1 \mathrm{~b}$ for an example), several researchers observed that children's symbolic representations are characterised by a similar effect of distance and size as their non-symbolic representations (De Smedt, Reynvoet, Swillen, Verschaffel, Boets, \& Ghesquière, 2009a; Holloway \& Ansari, 2009; Sekuler \& Mierkiewicz, 1977): kindergartners typically provide fast and accurate responses when the distance between the to be compared Arabic numerals is large respectively on smaller numbers, but answer slower and erroneously when the distance is small and the numbers become larger; these effects of distance and size also decrease with increasing age. 


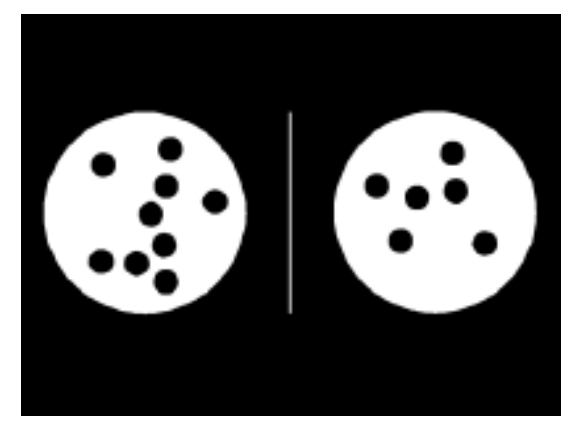

Figure 1a

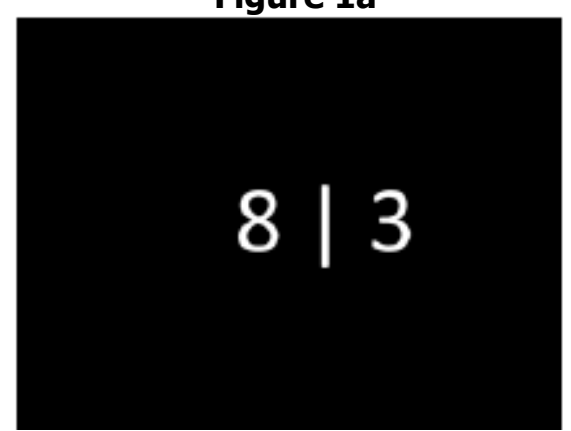

Figure $1 b$

Figure 1. Example of a non-symbolic (Figure 1a) and a symbolic comparison task (Figure 1b)

Third, the ability to represent numerosities on a mental number line also implies a mapping between numbers and space (e.g., Fias \& Fisher, 2005; Nuerk, Wood, \& Willmes, 2005). A classical task to examine these number-space interactions is the number line estimation task, in which children have to estimate the position of a (non-symbolic) numerosity or a (symbolic) number on an external number line (e.g., Booth \& Siegler, 2006; Siegler \& Opfer, 2003; see, respectively, Figure 2a and 2b). Developmental data have shown that numbers from larger ranges would obey a logarithmic representation, while smaller numbers would be mentally represented as linearly increasing magnitudes. With age, the mental representation would become linear for larger numbers too. This logarithmic-to-linear representation shift model has recently been challenged and has led to alternative accounts of these representations of number (Ebersbach, Luwel, Frick, Onghena, \& Verschaffel, 2008; Moeller, Pixner, Kaufmann, \& Nuerk, 2009).

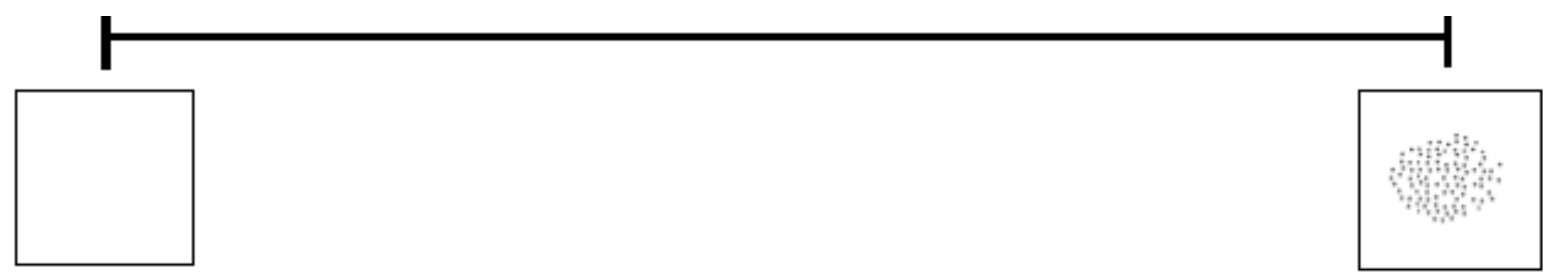

Figure 2a 
1

Figure 2b

Figure 2: Example of a non-symbolic (Figure 2a) and a symbolic number line estimation task (Figure 2b)

Finally, studies in typically developing children have shown that lower-order number sense, as measured with numerical magnitude comparison tasks and number line estimation tasks, is related with - and even predictive of - children's general mathematics achievement (Booth \& Siegler, 2006; De Smedt, Verschaffel, \& Ghesquière, 2009b; Halberda \& Feigenson, 2008; Holloway \& Ansari, 2009). Furthermore, children with learning disorders in mathematics are known to perform poorly on these two kinds of tasks (Butterworth, 2005; De Smedt et al., 2009a; Geary, Hoard, Nugent, \& Byrd-Craven, 2008; Landerl, Bevan, \& Butterworth, 2004; Rousselle \& Noël, 2007). However, little is known about how numerical magnitude representation is related to more specific mathematical skills and/or to specific components of higher-order number sense, such as fluently and flexibly calculating the answer to elementary additions and subtractions. Even though there are several theoretical arguments for postulating such specific relationships (Booth \& Siegler, 2008), few empirical data exist. Recent work of Vanbinst, Ghesquière, and De Smedt (2012) revealed that elementary school children's symbolic numerical magnitude processing skills are associated with their single-digit addition and subtraction calculation competencies. Their results showed that 8-year-olds with better access to magnitude representations from symbolic digits, retrieve more facts from their memory and are faster in executing fact retrieval as well as procedural strategies than their peers when solving single-digit sums and differences. Linsen, Verschaffel, Reynvoet, and De Smedt (2012) recently obtained similar results in the domain of multi-digit arithmetic, demonstrating that elementary school children with better numerical magnitude processing skills were more accurate and faster than their peers on multi-digit addition and subtraction problems, especially on problems that elicit clever computation strategies. Although these studies provided some first insights, more research is needed to establish more fine-grained and direct links between children's scores on the different measures of numerical magnitude 
representation and their performances and strategy competencies on elementary mathematical tasks.

\section{STIMULATING THE DEVELOPMENT OF NUMBER SENSE: INTERVENTION STUDIES}

As outlined above, performance on numerical magnitude comparison tasks and number line estimation tasks has been shown to be correlated with - and even predictive of - children's mathematical achievement in a broader sense. Accordingly, specific training on lower-order number sense could have a positive impact on arithmetical achievement. However, the number of intervention studies that have investigated this issue is limited and the results are heterogeneous, reaching from very small effects after intensive training to large effects after short-term interventions. In this section, we give a short overview of recent intervention studies that aimed at enhancing number sense in children before or at the beginning of systematic instruction in number and arithmetic at elementary school.

Several studies investigated the effects of playing linear number board games, aiming at supporting the development of a mental number line in children. Siegler and Ramani (2009; see also Ramani \& Siegler 2008, 2011; Siegler \& Ramani, 2008) showed that after just five intervention sessions of 15-20 minutes each, preschoolers from low-income families improved their performance on number comparison and number identification tasks. Furthermore, these children benefited more from subsequent learning of addition problems than children of a control group. Whyte and Bull (2008) also reported positive effects of linear number board game play on counting abilities, number understanding, and numerical estimation in pre-schoolers after four intervention sessions of 25 minutes each. Following the same theoretical model of a developing mental number line, Kucian et al. (2011) used a computer game in which children had to navigate a landing rocket onto the correct position on a horizontal number line. Pre-schoolers with and without diagnosed dyscalculia used this game for 15 minutes on five days a week, over five weeks. All participants improved performance not only on number line estimation tasks but also on specific arithmetic problems such as elementary addition and subtraction. 
Other studies focused on the development of an approximate understanding of numbers (see Gilmore, Attridge, \& Inglis, 2011) and used number comparison tasks in addition to linear number representations. Wilson, Dehaene, Dubois, and Fayol (2009) trained pre-schoolers from families with low-socio-economic status on comparing two numerical values that were presented as sets of dots, as Arabic number symbols, or as simple addition or subtraction problems. They used the computer game "The Number Race" (Wilson, Dehaene, Pinel, Revkin, Cohen, \& Cohen, 2006), in which the player has to solve such comparison tasks and to move the game characters on a linear board game. After six intervention sessions of 20 minutes each, the children's performance improved on symbolic number comparison tasks, but not on non-symbolic number comparison tasks or on addition tasks. Thus, there were positive effects only on some tasks that were directly trained but no transfer effects. Brankaer and Meeus (2009) studied low-achieving first-grade students who spent ten minutes a day, four days a week, over four weeks, on playing the "Number Race" game. While there were improvements on number comparison tasks, additions, and reading numbers, these improvements were not higher than in students of a control group that did not play the game.

Only small intervention effects were also found by Räsänen, Salminen, Wilson, Aunio, and Dehaene (2009), who compared the effects of the "Number Race" and the game "Graphogame-Math". In the latter game, the player has to select the correct visually presented number that corresponds to an auditory probe. Visual numbers are represented in organized dot patterns, number symbols or additions and subtractions. In this study, pre-schoolers with low numeracy played either the "Number Race" or the "Graphogame-Math" in a daily training session over a period of three weeks. While there were specific improvements on number comparison tasks compared to a control group of typically performing children, no significant training effects were found for other measures of arithmetic skills, such as object counting, addition, or subtraction. In a study with a similar design, Obersteiner, Reiss, and Ufer (in press) investigated first-graders from average classrooms playing one of two different versions of the "Number Race" game. While one version focused on approximate number processing such as number comparison and numerical estimation, the other focused on exact number processing and the recognition of organized dot patterns. After ten training sessions of 30 minutes each, the children showed significant improvements on the tasks that were directly trained, but the 
effects on performance on a paper-pencil arithmetic achievement test were very small. Moreover, no positive effects were found for the different subscales of the test, so that the relevance of specific basic number processing skills for different facets of arithmetical achievement remained unclear.

All in all, intervention effects of short-term training on very specific skills related to number sense seem to be relatively small and for the most part restricted to the tasks that were directly trained. In view of the available intervention studies, the use of linear number boards seems to be most promising. A possible explanation for the limited effects could be that the use of various types of tasks may be more beneficial than the repeated use of a very specific task such as number comparison. Moreover, explicitly teaching number concepts with a focus on the relationships between different aspects of numbers could contribute to a deeper conceptual understanding. As of yet, the cognitive link between lower-order number sense and higher-order arithmetical achievement is not sufficiently understood.

\section{CONCLUSION}

Number sense is crucial in daily life and therefore an important aspect of education. It is widely acknowledged that young children develop competencies related to number and space already before their entrance in school. These predominantly informal learning processes have been the focus of research over the last 60 years, starting with Piaget and his pioneering work on the development of the early number concept development (Piaget, 1957). While this developmental-psychological research has already elicited a first generation of intervention studies, the 1980s witnessed the emergence of a new set of large-scale projects as well as qualitative studies to investigate the contents, contexts and concepts of young children's learning of mathematics (e.g., Steffe, von Glasersfeld, Richards, \& Cobb, 1983) based on a new information-processing approach to early number development, emphasizing the development of children's counting skills as a stepping stone for mathematics education (Bobis, 1996; Young-Loveridge, 1999). During the last decade, our insights into young children's mathematical development were deepened and refined by a continuously increasing number of studies in the new domain of numerical cognition, strongly profiting from developments within cognitive and educational neuroscience. These studies did not only provide consistent empirical 
evidence for (very) young children's capacities in understanding and representing numerical magnitudes, but also pointed to the importance of this basic, lower-order number sense for children's further mathematical development. Although the relation between children's lower-order number sense and their higher-order mathematical understanding and skill was explicitly addressed in recent studies, our understanding of this relation is still limited. Future studies should try to deepen our insights into this topic, by analyzing both the type and the specificity of the relation between, on the one hand, children's understanding and representation of numerical magnitudes and, on the other hand, their further mathematical development, especially their fluency and flexibility in specific mathematical tasks. Such endeavors are not only important to deepen and refine our theoretical understanding, but also can offer building blocks to construct adequate tools for the diagnosis and stimulation of young children's number sense. Although the studies discussed above investigated young children's number sense with a variety of well-designed and methodologically sound tasks and provided evidence for the effectiveness of linear number boards to stimulate its development, further research is needed to disentangle the essential components of both the tasks used to tap children's developing number sense and the learning environments that optimize its development most.

\section{NOTES}

${ }^{1}$ Parts of this contribution are based on the project proposal of GOA/12/010 "Number sense: Analysis and improvement", authored by Lieven Verschaffel, Bert De Smedt, Jan Elen, Pol Ghesquière, Patrick Onghena, Bert Reynvoet, and Wim Van Dooren.

${ }^{2}$ It is important to note here that most studies on the development of number sense focused on children's understanding of natural numbers. Taking into account the focus of the contribution (early and elementary childhood education), we provide an overview of the major results of these studies in the domain of natural number. Evidently, children also have to develop an adequate understanding of non-natural numbers. As repeatedly shown in research, children's conceptions of non-natural numbers are frequently biased by their natural number understanding (= natural number bias). We refer the interested reader to Vamvakoussi, Christou, and Van Dooren (2010) and Vamvakoussi, Christou, Mertens, and Van Dooren (2011) for more information on this topic. 


\section{REFERENCES}

Ansari, D., \& Karmiloff-Smith, A. (2002). Atypical trajectories of number development: A neuroconstructivist perspective. Trends in Cognitive Sciences, 6, 511-516.

Berch, D. B. (2005). Making sense of number sense: Implications for children with mathematical disabilities. Journal of Learning Disabilities, 38, 333-339.

Bobis, J. (1996). Visualisation and the development of number sense with kindergarten children. In J. Mulligan, \& M. Mitchelmore (Eds.), Children's Number Learning: A Research Monograph of the Mathematics Education Group of Australasia and the Australian Association of Mathematics Teachers. Adelaide, Australia: AAMT.

Booth, J. L., \& Siegler, R. S. (2006). Developmental and individual differences in pure numerical estimation. Developmental Psychology, 41, 189-201.

Booth, J. L., \& Siegler, R. S. (2008). Numerical magnitude representations influence arithmetic learning. Child Development, 79, 1016-1031.

Brankaer, C. \& Meeus, H. (2009). De getallenrace: onderzoek naar het effect van een remediëringsprogramma bij zwakke rekenaars uit het eerste leerjaar [The Number Race game: a study on the effectiveness of this intervention in first graders with mathematical difficulties] (Unpublished master's thesis). University of Leuven, Faculty of Psychology and Educational Sciences, Leuven, Belgium.

Butterworth, B. (2005). Developmental dyscalculia. In J. I. D. Campbell (Ed.), Handbook of mathematical cognition (pp. 455-467). Hove, UK: Psychology Press.

Cirino, P. T., \& Berch, D. B. (2010). Introduction to the special issue: Perspectives on math difficulty and disability in children. Learning and Individual Differences, 20, 61-62.

De Smedt, B., Reynvoet, B., Swillen, A., Verschaffel, L., Boets, B., \& Ghesquière, P. (2009a). Basic number processing and difficulties in single-digit arithmetic: Evidence from Velo-Cardio-Facial Syndrome. Cortex, 45, 177-188.

De Smedt, B., Verschaffel, L., \& Ghesquière, P. (2009b). The predictive value of numerical magnitude comparison for individual differences in mathematics achievement. Journal of Experimental Child Psychology, 103, 469-479.

Dehaene, S. (1997). The number sense: How the mind creates mathematics. London, UK: Penguin Press.

Dehaene, S. (2001). Précis of the number sense. Mind \& Language, 16, 16-36. 
Dowker, A. (2005). Individual differences in arithmetic. Implications for psychology, neuroscience and education. New York: Psychology Press.

Ebersbach, M., Luwel, K., Frick, A., Onghena, P., \& Verschaffel, L. (2008). The relationship between the shape of the mental number line and familiarity with numbers in 5-to 9-year old children: Evidence for a segmented linear model. Journal of Experimental Child Psychology, 99, 1-17.

Fias, W., \& Fisher, M. H. (2005). Spatial representation of numbers. In: J. I. D. Campbell (Ed.), Handbook of mathematical cognition (pp. 43-54). Hove, UK: Psychology Press.

Gallistel, C. R., \& Gelman, R. (2000). Non-numerical cognition: From reals to integers. Trends in Cognitive Sciences, 4, 59-65.

Gallistel, C. R., \& Gelman, R. (2005). Mathematical cognition. In K. Holyoak, \& R. Morrison (Eds.), The Cambridge Handbook of Thinking and Reasoning (pp. 559588). Cambridge, UK: Cambridge University Press.

Geary, D. C. (2010). Mathematical disabilities: Reflections on cognitive, neuropsychological, and genetic components. Learning and Individual Differences, 20, 130-133.

Geary, D. C., Hoard, M. K., Nugent, L., \& Byrd-Craven, J. (2008). Development of number line representations in children with mathematical learning disability. Developmental Neuropsychology, 33, 277-299.

Gilmore, C., Attridge, N., \& Inglis, M. (2011). Measuring the approximate number system. The Quarterly Journal of Experimental Psychology, 64, 2099-2109.

Griffin, S. (2002). The development of math competence in the preschool and early school years: Cognitive foundations and instructional strategies. In J. M. Royer (Ed.), Mathematical cognition (pp. 1-32). Greenwich, CT: Information Age Publishing.

Halberda, J., \& Feigenson, L. (2008). Developmental change in the acuity of the "Number sense": The approximate number system in 3-, 4-, 5-, and 6-year-olds and adults. Developmental Psychology, 44, 1457-1465.

Hatano, G. (2003). Foreword. In A. J. Baroody \& A. Dowker (Eds.), The development of arithmetic concepts and skills (pp. xi-xiv). Mahwah, NJ: Lawrence Erlbaum Associates.

Holloway, I. D., \& Ansari, D. (2009). Mapping numerical magnitudes onto symbols: The numerical distance effect and individual differences in children's mathematics achievement. Journal of Experimental Child Psychology, 103, 17-29. 
Kaufmann, L., \& Dowker, A. (2009). Typical development of numerical cognition: Behavioral and neurofunctional issues [special issue]. Journal of Experimental Child Psychology, 103.

Kucian, K., Grond, U., Rotzer, S., Henzi, B., Schönmann, C., Plangger, F., et al. (2011). Mental number line training in children with developmental dyscalculia. NeuroImage, 57, 782-795.

Landerl, K., Bevan, A., \& Butterworth, B. (2004). Developmental dyscalculia and basic numerical capacities: A study of 8-9-year-old students. Cognition, 93, 99125.

Linsen, S., Verschaffel, L., Reynvoet, B., \& De Smedt, B. (2012). Numerical magnitude processing and individual differences in children's multi-digit subtraction. Manuscript submitted for publication.

Lipton, J. S., \& Spelke, E. S. (2005). Preschool children's mapping of number words to nonsymbolic numerosities. Child Development, 76, 978-988.

McIntosh, A., Reys, B. J., \& Reys, R. E. (1992). A proposed framework for examining basic number sense. For the Learning of Mathematics, 12(3), 2-8.

Moeller, K., Pixner, S., Kaufmann, L., \& Nuerk, H.C. (2009). Children's early mental number line: Logarithmic or decomposed linear? Journal of Experimental Child Psychology, 103, 503-515.

Nickerson, S. D., \& Whitacre, I. (2010). A local instruction theory for the development of number sense. Mathematical Thinking and Learning, 12, 227252.

Noël, M. P., Rousselle, L., \& Mussolin, C. (2005). Magnitude representation in children. Its development and dysfunction. In J. I. D. Campbell (Ed.), Handbook of mathematical cognition (pp. 179-195). Hove, UK: Psychology Press.

Nuerk H. C., Wood, G., \& Willmes, K. (2005). The universal SNARC effect: The association between number magnitude and space is amodal. Experimental Psychology, 52,187-94.

Obersteiner, A., Reiss, K., \& Ufer, S. (in press). How training on exact or approximate mental representations of number can enhance first-grade students' basic number processing and arithmetic skills, Learning and Instruction. doi:10.1016/j.learninstruc.2012.08.004

Piaget, J. (1957). Logic and psychology. Oxford, UK: Basic Books. 
Piazza, M., Facoetti, A., Trussardi, A. N., Berteletti, I., Conte, S., Lucangeli, D., Dehaene, S., \& Zorzi, M. (2010). Developmental trajectory of number acuity reveals a severe impairment in developmental dyscalculia. Cognition, 116, 33-41.

Ramani, G. B. \& Siegler, R. S. (2008). Promoting broad and stable improvements in low-income children's numerical knowledge through playing number board games. Child Development, 79, 375-394.

Ramani, G. B. \& Siegler, R. S. (2011). Reducing the gap in numerical knowledge between low- and middle-income preschoolers. Journal of Applied Developmental Psychology, 32, 146-159.

Räsänen, P., Salminen, J., Wilson, A. J., Aunio, P., \& Dehaene, S. (2009). Computerassisted intervention for children with low numeracy skills. Cognitive Development, 24, 450-472.

Rousselle, L., \& Noël, M. P. (2007). Basic numerical skills in children with mathematics learning disabilities: A comparison of symbolic vs non-symbolic number magnitude. Cognition, 102, 361-395.

Sekuler, R., \& Mierkiewicz, D. (1977). Children's judgments of numerical inequality. Child Development, 48, 630-633.

Siegler, R. S., \& Opfer, J. E. (2003). The development of numerical estimation: Evidence for multiple representations of numerical quantity. Psychological Science, 14, 237-243.

Siegler, R. S., \& Ramani, G. B. (2008). Playing linear numerical board games promotes low-income children's numerical development. Developmental Science, $11,655-661$.

Siegler, R. S., \& Ramani, G. B. (2009). Playing linear number board games-but not circular ones-improves low-income preschoolers' numerical understanding. Journal of Educational Psychology, 101, 545-560.

Steffe, L. P, von Glasersfeld, E., Richards, J., \& Cobb, P. (1983). Children's counting types: Philosophy, theory and application. New York: Praeger Scientific.

Vamvakoussi, X., Christou, K. P., Mertens, L., \& Van Dooren, W. (2011). What fills the gap between discrete and dense? Greek and Flemish students' understanding of density. Learning and Instruction, 21, 676-685.

Vamvakoussi, X., Christou, K. P., \& Van Dooren, W. (2010). Greek and Flemish students' understanding of the density of rational numbers: More similar, than different. Proceedings of the $34^{\text {th }}$ Conference of the International Group for the 
Psychology in Mathematics Education (Vol 4., pp. 249-256). Belo Horizonte, Brazil: PME.

Vanbinst, K., Ghesquière, P., \& De Smedt, B. (2012). Numerical magnitude representations and individual differences in children's arithmetic strategy use. Mind, Brain and Education, 6, 129-136.

Verschaffel, L., \& De Corte, E. (1996). Number and arithmetic. In A. Bishop, K. Clements, C. Keitel, \& C. Laborde (Eds.), International handbook of mathematics education. Part I (pp. 99-138). Dordrecht, The Netherlands: Kluwer.

Verschaffel, L., Greer , B., \& De Corte, E. (2007). Whole number concepts and operations. In F. K. Lester (Ed.), Second handbook of research on mathematics teaching and learning (pp. 557-628). Greenwich, CT: information Age Publishing.

Wagner, D., \& Davis, B. (2010). Feeling number: Grounding number sense in a sense of quantity. Educational Studies in Mathematics, 74, 39-51.

Whyte, J. C. \& Bull, R. (2008). Number games, magnitude representation, and basic number skills in preschoolers. Developmental Psychology, 44, 588-596.

Wilson, A. J., Dehaene, S., Dubois, O., \& Fayol, M. (2009). Effects of an adaptive game intervention on accessing number sense in low-socioeconomic-status kindergarten children. Mind, Brain, and Education, 3, 224-234.

Wilson, A. J., Dehaene, S., Pinel, P., Revkin, S. K., Cohen, L., \& Cohen, D. (2006). Principles underlying the design of "The Number Race", an adaptive computer game for remediation of dyscalculia. Behavioral and Brain Functions, 2: 19, doi:10.1186/1744-9081-2-19.

Xu, F., \& Arriaga, R. (2007). Number discrimination in 10-month-old infants. British Journal of Developmental Psychology, 25, 103-108.

Xu, F., \& Spelke, E. S. (2000). Large number discrimination in 6-month-old infants. Cognition, 74, B1-B11.

Yang, D. C., Li, M. N., \& Lin, C. I. (2008). A study of the performance of 5 th graders in number sense and its relationship to achievement in mathematics. International Journal of Science and Mathematics Education, 6, 789-807.

Young $\square$ Loveridge, J. M. (1999). The acquisition of numeracy. Research Information for Teachers, 1(12), 1-8. 